\title{
O ensino da Matemática ao deficiente intelectual: projetos de trabalho em uma perspectiva contextualizada e interdisciplinar
}

\author{
Amanda Drzewinski de Miranda* \\ Nilcéia Aparecida Maciel Pinheiro**
}

\section{Resumo}

Este texto discute a ressignificação do processo ensino e aprendizagem de Matemática e Ciências de alunos com deficiência intelectual ao aplicar um projeto contextualizado e interdisciplinar. Apresenta, assim, resultados de uma pesquisa, a qual foi desenvolvida na Escola de Educação Básica na Modalidade Educação Especial na Área Intelectual e Múltiplas, do município de Ponta Grossa, Paraná, junto a seis discentes do $2^{\circ}$ ano do Ensino Fundamental. A obtenção dos dados resultantes da aplicação das intervençôes pedagógicas se deu por meio de uma pesquisa qualitativa de cunho interpretativo. Durante a aplicaçáo do projeto de trabalho, observou-se que os alunos mostraram-se motivados em aprender, assumindo a posição de ativo perante o conhecimento. Além disso, verificou-se em todas as etapas do desenvolvimento do projeto que os educandos demonstravam confiança em expor suas ideias, o que propiciou um clima encorajador, de forma que se mostravam capazes em aprender. Os resultados demostram que a proposta favoreceu a construção de conceitos de Matemática e Ciências alicerçados em situaçôes do cotidiano, bem como a acessibilidade desses conhecimentos para alunos deficientes intelectuais.

Palavras-chave: Educação Especial; Deficiência intelectual; Ensino de Matemática; Ensino de Ciências.

* Doutoranda em Ensino de Ciência e Tecnologia pela Universidade Tecnológica Federal do Paraná, Ponta Grossa, Paraná, Brasil.

** Professora Doutora da Universidade Tecnológica Federal do Paraná, Ponta Grossa, Paraná, Brasil. 


\section{Teaching Mathematics to students with intellectual disability: projects of report in a contextualized and interdisciplinary perspective}

\section{Abstract}

This paper discusses the new meaning of the teaching and learning process of Math and Science for students with intellectual disability upon applying a project contextualized and interdisciplinary. It presents, thou, results of a research, which was developed in a school of basic education in the area of special education in the city of Ponta Grossa, Paraná, with six students from the second year of the Primary School. The results obtained through the pedagogical intervention were done through a qualitative research. During the time the project was going on, it was observed that the students were motivated to learn, very active in face to knowledge. Besides this, it was verified in all the stages of the project that the students showed confidence to give their ideas, providing an encouraging environment, thus they were more capable to learn. The results revealed that the proposal was good to build Math and Science concepts based on the daily situations, as well as the accessibility of this knowledge to students with intellectual disability.

Keywords: Special Education; Intellectual disability; Math teaching; Science teaching.

\section{Introdução}

O processo educacional da pessoa com deficiência foi marcado por uma história de segregação. Contudo, vários movimentos, como o de inclusão social, têm buscado defender e discutir as condiçóes necessárias para sua aprendizagem, incentivando a elaboração de políticas públicas condizentes com suas necessidades educativas.

O amplo campo da Educação Especial atende os estudantes com deficiência, transtorno global do desenvolvimento, altas habilidades e superdotação, sendo que, nesta pesquisa, abordou-se a deficiência intelectual.

Em se tratando de deficiência intelectual, segundo Glat e Fernandes (2005), apesar de as pesquisas e políticas educacionais em vigor assegurarem a inclusão social, a pessoa com deficiência intelectual ainda tem sido excluída, por ser considerada e tratada como doente mental e diagnosticada como incapaz de aprender. Contudo, precisa-se modificar o enfoque em torno das dificuldades e centrar o processo de apropriaçáo do conhecimento de acordo com suas possibilidades de aprendizagem e buscar alternativas de trabalho pedagógico para que a educaçáo escolar se efetive de fato.

Dessa forma, a pessoa com deficiência tem o direito a uma educação de qualidade, a qual considere as suas especificidades de aprendizagem a fim de promover sua autonomia. Neste contexto, os saberes de Matemática e de Ciências tornam-se 
indispensáveis para a formação integral do cidadão devendo, portanto, ser trabalhados na escola em uma abordagem dinâmica e prazerosa, a qual desperte a motivaçáo em aprender. Assim, cabe ao professor propor intervençôes pedagógicas, as quais procurem inserir o educando com deficiência intelectual no processo de ensino e aprendizagem, evidenciando a importância e a utilidade do conhecimento matemático e científico em seu cotidiano.

Os estudos realizados por Vygotsky (1997) salientam que a pessoa com deficiência intelectual, além da dificuldade em aprender conteúdos escolares, possui poucos conceitos científicos elaborados, fato que interfere na aprendizagem, quer seja na esfera conceitual ou social. Entretanto, a escola não deve acomodar-se diante da deficiência, mas criar estratégias para que o aluno aprenda a lidar e superar suas dificuldades, promovendo a aprendizagem com significado.

Para isso, faz-se necessário promover estratégias de aprendizagem cooperativa, que oportunizem aos educandos a tomada de decisão sobre o planejamento do seu trabalho, aplicando de forma autônoma o que aprenderam.

Desse modo, com o intuito de propiciar o desenvolvimento cognitivo, social e afetivo do discente com deficiência intelectual, por meio de encaminhamentos sustentados pelo tripé "curiosidade, investigação e descoberta" (MARTINS, 2001), conduziu-nos a escolher ações pedagógicas fundamentadas em projetos de trabalho. Para que os conceitos matemáticos fossem contextualizados e que a matemática pudesse ser utilizada na melhoria da qualidade de vida dos alunos com deficiência intelectual.

O trabalho pedagógico fundamentado na metodologia de projetos, como aponta Martins (2001), Nogueira (2007 e 2008) e Mendes (2009), é uma forma de conduzir o aluno a participar ativamente, por isso ele se torna corresponsável pela aprendizagem. Assinalam ainda que, por meio de projetos, é possível contextualizar os conteúdos, favorecendo a interdisciplinaridade.

A partir desse pressuposto, este estudo norteou-se na indagação: quais os resultados que poderemos verificar no ensino e aprendizagem de Matemática dos alunos com deficiência intelectual ao aplicar um projeto de trabalho interdisciplinar com Ciências?

Para tanto, buscaram-se aportes teóricos que embasassem discussóes sobre o ensino da Matemática para o deficiente intelectual em um contexto interdisciplinar com Ciências, bem como a utilização da metodologia de projetos a qual fundamentou esta pesquisa.

\section{Caracterizando a deficiência intelectual}

A terminologia e conceituação de "deficiência intelectual", nos últimos anos, vêm passando por um processo constante de reformulaçáo, no sentido de buscar um termo ou expressáo mais apropriado para definir a alteração do desenvolvimento humano. À medida que novos estudos teóricos surgiram, as definiçóes estabelecidas e utilizadas anteriormente, tais como idiota, subnormal, retardado mental e excepcional, foram substituídas por deficiente mental e, recentemente, designada deficiente intelectual. 
A American Association on Intellectual and Developmental Disabilities ${ }^{2}$ (AAIDD) considera o termo deficiência intelectual como sendo:

Deficiência caracterizada por limitaçóes significativas no funcionamento intelectual e no comportamento adaptativo, como expresso nas habilidades práticas, sociais e conceituais, originandose antes dos dezoito anos. (SHOGREN, et al, 2010, p. 6).

De acordo com Coll, Marchesi e Palacios (2004), a deficiência intelectual é considerada uma condição permanente, porém, não imutável, por não se referir ao comprometimento da mente como um todo, e sim, uma limitaçáo no funcionamento intelectual. Entretanto, ao ser estimulado, por meio de intervençốes utilizando recursos adequados, a pessoa com deficiência intelectual, em muitos casos, pode ter um bom desempenho, tanto nas habilidades adaptativas quanto nas acadêmicas, tão valorizadas pela sociedade. Portanto, segundo Coll, Marchesi e Palacios (2004, p. 208), a educação das pessoas com deficiência deve "[...] contribuir para incrementar seu potencial cognitivo e não apenas o afetivo e o de relaçáo social, e que com isso contribua para configurar a identidade e maturaçáo pessoal de acordo com as limitaçôes de cada uma”.

Para Mantoan (1997), os alunos com deficiência intelectual são capazes de aprender por meio de um currículo embasado em conteúdos organizados de maneira construtivista, pelo fato de direcionarem a pessoa com deficiência a exercer seu poder de decisão, por meio de iniciativa própria.

Assim, a abordagem nessa perspectiva educacional contrapóe-se a uma concepção meramente diagnóstica. Com isso, ressaltamos o papel das intervençóes de caráter intencional no campo educacional, com objetivos definidos, de acordo com as características peculiares do aluno, o qual cria possibilidades para o avanço do seu desenvolvimento cognitivo.

Salienta-se, então, que o processo educativo deve configurar-se de modo dinâmico e motivador, colocando o aluno como sujeito do processo. Faz-se necessário propiciar todas as condiçóes para que o aluno com deficiência intelectual adquira e desenvolva habilidades que possibilitem sua melhor inclusáo social, fazendo, portanto, que ele exerça o papel de cidadáo na sociedade.

\section{O ensino de Matemática e de Ciências}

Matemática e Ciências mostram-se presentes em todos os momentos de nossa vida, em experiências mais triviais como contar, comparar quantidades ou escolher um alimento saudável, porém nem todos dominam esses conhecimentos.

Nesse sentido, a escola desempenha um papel importante, de proporcionar a todos os alunos o acesso e a oportunidade de aprenderem os conteúdos dessas áreas do conhecimento.

Sendo assim, em relação ao conhecimento matemático, Dante aponta a importância em ensiná-lo, 
[...] mais que nunca, precisamos de pessoas ativas e participantes, que deverão tomar decisóes rápidas e, tanto quanto possível, precisas. Assim, é necessário, formar cidadãos matematicamente alfabetizados, que saibam como resolver, de modo inteligente, seus problemas de comércio, economia, administração, engenharia, medicina, previsão do tempo e outros da vida diária. (DANTE, 1989, p. 15).

Semelhantemente, na Declaração de Budapeste é argumentada a importância do ensino de Ciências.

Para que um país esteja em condiçóes de atender às necessidades fundamentais de sua população, o ensino de ciências e tecnologia é um imperativo estratégico [...]. Hoje, mais do que nunca, é necessário fomentar e difundir a alfabetização científica, em todas as culturas e em todos os setores da sociedade. (DECLARAÇÃO DE BUDAPESTE, 1999, p. 3).

Cada vez mais se tem certeza que o conhecimento matemático e científico das ciências naturais é instrumento para que o sujeito se coloque na posiçáo de ativo, capaz de tomar decisóes, com a finalidade de contribuir para o desenvolvimento da sociedade. Para isso, o conhecimento da Matemática e da Ciência precisa estar ao alcance de todos, de forma que seu ensino seja democratizado.

Com isso, o conhecimento matemático e científico das ciências naturais, trabalhados com alunos com deficiência intelectual, fundamentou-se por muito tempo meramente em atividades rotineiras e repetitivas. Contudo, é preciso romper as concepçóes que preconizam as limitaçóes, uma vez que, como afirma Vygotsky (1997), o desenvolvimento do deficiente intelectual não difere do desenvolvimento das demais crianças.

Assim, o professor, segundo D’Ambrósio (2001a), necessita focar sua ação pedagógica de modo que as experiências escolares contribuam e forneçam elementos para o aluno ser atuante, contemplando que a matemática e as ciências naturais são peças importantes na construçáo da cidadania, visto que o aluno se servirá desses conhecimentos para entender e transformar sua realidade.

Logo, as metodologias tradicionais, fundamentadas na repetição, na mecanização em lista de exercícios incansáveis para o ensino de Matemática e de Ciências, mostram-se pouco eficientes para auxiliar o aluno com deficiência intelectual a criar, com autonomia, soluçóes para os problemas que enfrenta. Há necessidade de romper a concepção absolutista de ensino de Ciências e de Matemática. Uma das possibilidades é a realização de projetos de trabalho, cuja dinâmica envolve uma prática social que requer o envolvimento do aluno em atividades significativas.

\section{Etapas de projetos de trabalho}

A metodologia de projetos de trabalho preconiza educação pela ação, a partir da reconstrução das experiências de vida do aluno. Logo, a experiência e aprendizagem mantêm elos, os quais propiciam condiçóes para que o aluno resolva seus problemas. Nessa perspectiva, a concepção da pedagogia de projetos está pautada em práticas pedagógicas significativas para o aluno. 
Assim, no início, um projeto, as intençôes e os objetivos que se pretendem alcançar devem estar explícitos, bem como o que se quer realizar, tanto por parte do aluno quanto do professor. Para sua realização, Nogueira (2008, p. 79-94) enumera cinco etapas norteadoras: "[...] planejamento, execução, depuração, apresentação e avaliação, que auxiliam o professor nesta pedagogia”. Essas etapas têm como propósito estruturar o raciocínio do aluno.

A primeira etapa, o planejamento, é a fase em que os alunos são orientados a estruturar as açôes que desenvolverão durante a realizaçáo do projeto. Segundo Nogueira (2008, p. 81-82), o professor deve provocar os seguintes questionamentos:

- O quê? Sobre o que falaremos/pesquisaremos? O que faremos no projeto?

- Por quê? Por que trataremos deste tema? Quais são os objetivos?

- Como? Como realizaremos esse projeto? Como operacionalizaremos? Como podemos dividir as atividades entre os membros do grupo? Como apresentaremos o projeto?

- Quando realizaremos as etapas planejadas?

- Quem realizará cada uma das atividades? Quem se responsabilizará pelo quê?

- Quais serão os recursos - materiais e humanos - necessários para a perfeita realização do projeto?

Essa primeira fase de elaboraçáo do projeto abrange a escolha do tema. Essa escolha deve ser realizada em ação conjunta, entre o professor e os alunos, e o papel do professor, nesse momento, é de orientá-los para organizar suas ideias por meio de questionamentos críticos e construtivos. Todavia, normalmente, um planejamento pode sofrer ajustes necessários no decorrer da execução, tendo em vista uma estruturação satisfatória.

A segunda etapa é a fase em que se coloca em prática tudo o que foi planejado, a implementação ou execução. Nesse momento, cabe ao professor auxiliar o aluno na busca de informaçóes que ampliem e completem a proposta do trabalho, além de facilitar o acesso a recursos materiais e humanos. Nessa etapa é fundamental que o professor motive os alunos para que eles se envolvam no desenvolvimento das atividades.

A depuração, que abrange a terceira etapa, é o momento que tem como principais características a autoavaliação e autocrítica sobre as açóes que já foram realizadas, com a finalidade de verificar e refletir sobre as falhas existentes e melhorar a qualidade do projeto. Segundo Nogueira (2008, p. 86), “[...] é importante que o aluno entenda que ele pode: (re) planejar, (re) elaborar, (re) produzir, criar novas hipóteses, mudar percursos, alterar rotas e processos", oportunizando momentos de reflexão.

À medida que o projeto se desenvolve, o aluno estabelece relaçôes até então não consideradas, mas que vão sendo construídas no próprio desenvolvimento do projeto. Assim, o trabalho pedagógico com projeto atende a possibilidade de o aluno 
desenvolver não somente o conteúdo curricular, mas permite-lhe problematizar o mundo lá fora, criando condiçóes para buscar respostas para as suas dúvidas, para compreendê-las visando a sua transformação.

A quarta etapa é a apresentação, na qual os alunos irão consolidar tudo o que aprenderam da temática do projeto, ou seja, os conhecimentos construídos e adquiridos durante o seu desenvolvimento. Essa etapa pode ser realizada para toda a comunidade escolar, por meio da exposição de todo o trabalho. $\mathrm{O}$ aluno expóe tudo o que aprendeu e descobriu durante a pesquisa, assim, a "[...] apresentação servirá para coroar o "[...] término" do projeto, o qual dará oportunidade à equipe de expor suas descobertas, hipóteses, criaçóes e conclusôes". (NOGUEIRA, 2008, p. 88). Em paralelo com a etapa da apresentação, o professor pode realizar a avaliação do projeto.

Seguindo as etapas do projeto, parte-se para a avaliação, que consiste em dois momentos: um de ordem interna, sendo que cada aluno recapitula o que foi aprendido, em um sistema de autoavaliação, por meio de um diário de bordo. Outro de ordem externa, em que o professor irá estabelecer critérios de acordo com os objetivos, do conteúdo estudado. Nesse momento, é importante que o professor considere os seguintes aspectos, mencionados por Hernández e Ventura (1998): Quais conhecimentos foram adquiridos? Que mudanças de atitude foram observadas? Que crescimento os alunos obtiveram? O aluno envolveu-se durante todo o processo? Quais foram as falhas?

A práxis pedagógica fundamentada em projeto de trabalho nos parece ser uma forte estratégia para o tratamento dos problemas de modo interdisciplinar. Dessa forma, pressupõe a articulação com as diversas áreas do conhecimento, inclusive a participação de profissionais fora do contexto escolar.

\section{A interdisciplinaridade e a contextualização}

De acordo com Santomé (1998) a proposta da intervenção pedagógica interdisciplinar e contextualizada a partir de projetos de trabalho não é algo recente. Logo, para se trabalhar com projetos, é fundamental que o professor assuma uma postura na qual compreenda que o conhecimento construído possui uma estreita ligaçáo com o contexto em que é utilizado. Para Pais (2006), as situaçôes de aprendizagem precisam oferecer sentido para o aluno e isso se consegue com a contextualização do saber. Entretanto, para esse autor, não basta o destaque do contexto, é preciso fazer várias articulaçôes com fatos históricos, sociais, políticos, econômicos, ou seja, em várias áreas do conhecimento. Assim, a articulaçáo de conteúdos pertencentes às diversas áreas contribui para a percepção do contexto social.

Segundo Morin (2003), a interdisciplinaridade "[...] é desafio da globalidade”. O autor ressalta que o sistema de ensino ainda converge para compartimentar as disciplinas, ensinando os alunos a isolar os objetos e dissociar os problemas. Ainda complementa que o complexo é reduzido ao simples, de forma que as contradiçôes e as desordens devem ser eliminadas. Opondo-se a essa dissociaçáo, ele afirma que contextualizar e articular os conhecimentos são uma qualidade fundamental para o desenvolvimento da mente humana, ou seja, é necessário ser desenvolvida, e não atrofiada. 
Para realizar um trabalho interdisciplinar é preciso que o professor coordene suas açôes pedagógicas para que exista um diálogo entre as disciplinas. Para tanto, não é necessário modificar o objeto de estudo da disciplina, mas a busca em estabelecer relaçôes mais fortes entre elas. Conforme Nogueira (2007), esse momento é importante, pois é necessário coordenar de maneira integrada os objetivos, as atividades, os procedimentos, as atitudes, os planejamentos, a troca, o diálogo, para que ocorra um intercâmbio de conhecimento, saberes entre as disciplinas.

Ao se tratar de contextualização, os autores Pavanello (1995), Brousseau (1996) e Tufano (2001) enfatizam que o contexto deve ser orientado de modo que a prática pedagógica esteja vinculada a uma situação que dê significado aos saberes que serão adquiridos. É uma maneira de propor ao aluno situaçóes que provoquem discussões, a fim de articular os conhecimentos, de modo interdisciplinar. Portanto, é uma ação desenvolvida para localizar a pessoa em determinado lugar, no tempo e espaço que se deseja.

Com isso, a contextualização é um modo de despertar ideias, como uma forma de argumentaçâo, e implica trazer os fatores externos para serem trabalhados dentro da escola, para que sejam compreendidos dentro da esfera histórica, social e cultural. A partir dessas consideraçôes, percebe-se que o ensino interdisciplinar e contextualizado traz à tona a compreensáo de por que estudar um determinado conteúdo, ampliando as possibilidades de o aluno entender que o conhecimento é historicamente construído e está em constante evolução.

Contudo, Pinheiro (2005) chama a atenção para que se entenda que a organização pedagógica fundamentada nos princípios de contextualização e interdisciplinaridade pretende relacionar os conhecimentos adquiridos na escola com a vida do aluno, por meio de situaçóes problematizadoras que conduzam o aluno a tomar suas próprias decisóes.

\section{Desenvolvimento da pesquisa}

A pesquisa foi realizada na Escola de Educação Básica Professora Maria de Lourdes Canziani na Modalidade de Educação Especial, sendo que a Associação de Pais e Amigos dos Excepcionais - APAE de Ponta Grossa, Paraná, é a entidade mantenedora.

Nesse contexto, participaram da pesquisa 6 alunos com laudo médico de deficiência intelectual, matriculados no $2^{\circ}$ ano $0^{3}$ do Ensino Fundamental. Os alunos compóem a turma, a qual a pesquisadora é professora. Dentre esses alunos, três eram do sexo feminino e três do sexo masculino com a idade cronológica entre 10 e 12 anos, os quais demonstravam muitas dificuldades em aprender conceitos de Matemática.

Com o propósito de desenvolver uma prática pedagógica reflexiva, a qual criasse possibilidades diferenciadas para ensinar o conteúdo de Matemática e Ciências, procurou-se selecionar uma metodologia compatível com os objetivos da pesquisa, com as características do objeto de estudo e com o contexto da investigaçáo. Em face disso, constatou-se que a natureza da presente pesquisa seria de abordagem qualitativa tendo cunho interpretativo. 
Para isso, utilizou-se o diário de campo para o registro dos dados coletados. Conforme Minayo (1994), o diário é um instrumento ao qual podemos recorrer em qualquer momento da pesquisa. Nele, diariamente, são expostas as percepçóes, as angústias, os questionamentos e as informaçóes que não são obtidos por meio das entrevistas.

Propusemos desenvolver estratégias pedagógicas que possibilitassem a melhor aprendizagem em Matemática, de forma contextualizada e interdisciplinar, enfocando uma abordagem dinâmica e efetiva, buscando dar sentido a tudo que está sendo aprendido, em que o aluno é participante ativo. Com isso, desvinculando o ensino da Matemática centrado em práticas pedagógicas com ênfase na memorização e repetição.

Assim, para elucidar a escolha do tema, Nogueira (2008) sugere que o professor analise o contexto de vida dos discentes, a fim de formular problemas condizentes com a realidade deles. Baseado nessa análise, é possível, então, o professor e os alunos selecionarem o tema ou problema para ser tratado no projeto.

$\mathrm{Na}$ intenção de abordar essa perspectiva, a pesquisadora sugeriu a situação -problema relacionada com a festa de encerramento, que a escola realiza todo final de ano, articulando o tema com a realidade social da vida do aluno. A fase de escolha do tema ocorreu mediante sugestóes dos alunos e professor. O tema definido foi intitulado de Projeto "Preparação de uma Refeição", justificado pela necessidade dos alunos em aprender a organizar um cardápio de acordo com as necessidades nutricionais, identificando os alimentos benéficos à saúde, bem como proceder à higienização e preparaçáo desses.

Após a escolha do tema, é necessário estruturar o projeto por meio do planejamento, que constitui a segunda etapa da metodologia de projetos. Essa etapa do projeto é considerada como um processo por meio do qual o aluno desenvolverá sua autonomia, no sentido de expor suas vontades e esboçar seus interesses.

Desse modo, os alunos observaram que um dos itens importantes que faz parte do planejamento da organização da festa é o cardápio. Para isso, sugeriu-se o estudo sobre a alimentação, para melhor entender sobre hábitos alimentares, obesidade, alimentação saudável, desperdício de alimentos, entre outros.

A próxima etapa é o momento em que se coloca em prática tudo o que foi planejado, a implementação ou execução, de acordo com Nogueira (2008). Assim, para efetivar essa fase, foram propostas atividades ${ }^{4}$, tais como: investigação da medida da quadra de esportes, palestra com a nutricionista, pesquisa de opinião sobre o cardápio preferido, entrevista com a cozinheira da escola, visita e compra de frutas na feira, preparação da salada de frutas, experiência de medida de capacidade, jogo do sistema monetário, álbum de valores e produtos e produção de livro de receitas. As atividades sugeridas contemplaram os conteúdos de Matemática e de Ciências propostos para o desenvolvimento do projeto, em uma abordagem contextualizada e interdisciplinar. 
Durante as atividades para a execução do projeto, os estudantes foram incentivados a socializar as suas ideias e percepçôes do conteúdo em estudo. Esse momento de socialização no projeto, de acordo com Santomé (1998), estimula a análise e comparação de opiniốes, nas quais os alunos aprendem a escutar o outro. Trata-se, assim, de expor o pensamento matemático oralmente, contribuindo para que o deficiente intelectual expresse suas ideias, desenvolvendo sua oralidade.

Uma das atividades para a execução do projeto está relacionada com a busca de fontes de informaçóes, que complementem e ampliem o conhecimento sobre o tema. Dentre as açôes definidas, está a inserção de uma palestra proferida por uma nutricionista especializada na área de estudo. Percebeu-se o quão foi significativa a palestra. Os alunos relataram oralmente seus hábitos alimentares, a fim de discutir os tipos de alimentos que cada família costumava consumir. Percebeu-se, por sua vez, que os educandos desconheciam informaçóes sobre a proporção adequada de alimentos que compóe uma refeição. Diante dessas dúvidas, a nutricionista salientou a importância dessa distribuição para o desenvolvimento da criança. Esse momento foi fundamental para que os alunos compreendessem a importância de manter hábitos alimentares saudáveis. Conforme Cachapuz (2000), considera-se que Educação em Ciências deve promover aprendizagem de conhecimentos que se tornem utilizáveis, integrados à prática de vida do aluno. Nessa perspectiva, o aluno deixa de ser apenas um aprendiz de conteúdo.

Dessa maneira, pode-se afirmar que os alunos, embora com limitações intelectuais, muitas vezes podem mostrar-se surpreendentes nas suas realizaçóes. Com isso, por meio de uma ação pedagógica adequada, deixa-se para trás a noção de que as dificuldades decorrentes da deficiência intelectual são condiçôes fixas e imutáveis (COLL; MARCHESI; PALACIOS, 2004).

A depuração, etapa seguinte, é uma fase importante no projeto de trabalho, porque se analisa tudo aquilo que se esperava atingir no projeto. Nessa etapa, alguns questionamentos são realizados aos alunos, a fim de orientá-los a refletir se os resultados alcançados foram satisfatórios ou não, e o que é preciso melhorar (NOGUEIRA, 2008).

Esse momento ocorreu nesta pesquisa quando a cozinheira comentou com os alunos participantes, que durante o lanche acontecia muito desperdício de alimento. Esse fato os preocupou, assim resolveram lançar uma campanha na escola contra o desperdício de comida. Desse modo, essa fase do projeto pode ser caracterizada como depuração, uma vez que se pretende a melhoria dos processos até então empregados. Conforme Nogueira (2008), na prática, a depuração não precisa acontecer em um momento estanque, mas durante a própria etapa de execução.

A próxima fase do projeto é definida por $\operatorname{Nogueira~}(2007$, p. 87) como exposição ou apresentaçáo. Nesse momento, os alunos expuseram para a comunidade escolar o que fizeram durante o projeto, bem como suas descobertas. Assim, para que essa atividade se efetivasse, durante as aulas anteriores, os alunos foram organizados em duplas. Com isso, cada dupla escolheu, dentre os materiais confeccionados durante a 
execução do projeto, qual gostaria de apresentar aos colegas. Em seguida, realizou-se o ensaio da apresentação, a fim de fazer alguma reformulação, caso houvesse necessidade. Optou-se por uma apresentação organizada para que os alunos se sentissem confiantes e seguros em relação ao que iriam expor.

$\mathrm{Na}$ organização dos materiais para a exposição, os alunos mostraram-se animados, porém, ansiosos e tensos. Notava-se a preocupação em relação a realização da apresentação, demonstrando, assim, o senso de comprometimento e responsabilidade dos estudantes, afinal, a exposiçâo dos trabalhos rompe as fronteiras da sala de aula.

De acordo com Nogueira (2007), a avaliação é a fase do projeto que pode gerar uma ótima oportunidade de estimular os alunos a realizar um feedback. De acordo com o PCN (BRASIL, 1998, p. 38), o aluno é considerado “[...] protagonista da construção de sua aprendizagem”. Portanto, devemos designar a ele o mesmo papel no que se refere à avaliação de sua aprendizagem. Dentro dessa perspectiva, oportunizou-se aos alunos um momento para que refletissem sobre a própria aprendizagem, por meio de um relato oral.

Foi, então, solicitado a eles que refletissem sobre alguns itens, tais como: atividades que gostaram de realizar; dificuldades encontradas na execução do projeto; o que falta entender sobre os assuntos estudados e se o que queriam saber no início do projeto foi respondido. Os alunos apresentaram oralmente suas reflexôes.

Para Toledo (2010), a autoavaliação contribui tanto para a formação intelectual quanto moral do aluno. Nos relatos realizados pelos alunos, foi possível observar a evolução deles quanto ao raciocínio e o uso do vocabulário adequado para caracterizar os conhecimentos matemáticos e científicos.

\section{Considerações finais}

Percebeu-se, no transcorrer das etapas desenvolvidas no projeto, que a ligação aos outros campos do conhecimento torna a Matemática "viva", contribuindo para a compreensão dos conceitos ensinados.

Assim, pelo fato da Matemática estar presente em muitas situaçóes do dia a dia, porém, muitas vezes náo percebida pelas pessoas, cabe ao professor orientar o aluno a descobrir a importância dela em sua vida. Logo, ensiná-lo a compreendê-la como algo acessível, ao invés de apresentá-la a um nível de dificuldade que, muitas vezes, torna-se inacessível para o aluno com deficiência intelectual.

Nessa perspectiva, as atividades propostas favoreceram as construçóes dos conceitos matemáticos alicerçados em situaçôes do cotidiano. Para isso, a Matemática escolar deve permear as necessidades do aluno enquanto cidadáo, tendo significado na sua vida cotidiana.

O aluno com deficiência intelectual elabora suas funçóes psíquicas superiores baseadas em situaçôes que se tornam significativas para ele. Diante disso, o educando esforça-se para pensar em estratégias para resolver um problema quando sua motivação e necessidades são consideradas. 
Sob esse enfoque, uma característica importante a ser destacada é a diversidade de atividades planejadas que surgiram na execução do projeto. Tais situaçóes provocavam curiosidade e despertavam interesse dos alunos, afinal, eles demonstravam expectativa em saber o que iriam pesquisar e realizar na aula seguinte. Nesse sentido, desencadeou-se, por meio do projeto, um ambiente propício para a aprendizagem de Matemática e Ciências. Logo, conduziu-se o aluno a estruturar o seu pensamento, capacitando-o a enfrentar as dificuldades do dia a dia.

Os conteúdos abordados, os quais surgiram a partir da pesquisa para elucidar os questionamentos sobre o tema, favoreceram o exercício da cidadania. As atividades propostas possibilitaram ao aluno compreender o uso do conhecimento matemático e científico como um conjunto de práticas sociais.

Notou-se que a liberdade de planejamento e execução das açôes planejadas em todas as etapas do projeto propiciou aos alunos a identificação dos problemas, bem como a busca de soluçóes. Tal proposta considera o professor um orientador e facilitador, o qual conduz o aluno a descoberta, por meio de seus questionamentos.

Vale reiterar que a aprendizagem, por meio de projetos de trabalho na perspectiva interdisciplinar e contextualizada, torna as aulas atrativas, as quais despertam o interesse do aluno para o conhecimento matemático. Além disso, se desejamos que o aluno deficiente intelectual se coloque no seu lugar de cidadão, é necessário que a escola oportunize experiências que promovam a participação e a integração social desse aluno, como princípios norteadores para o ensino e aprendizagem.

\section{Referências}

AAIDD (American Association on Intellectual and Developmental Disabilities). Intellectual disability: definition, classification, and systems of supports. Washington (DC): AAIDD, 2010.

BRASIL. Ministério da Educação. Secretaria de Educação Fundamental. Parâmetros Curriculares Nacionais: Matemática. Brasília: MEC/SEF, 1998.

BROUSSEAU, G. Os diferentes papéis do professor. In. PARRA, C.; SAIZ, I. (Orgs.). Didática da Matemática: reflexóes psicopedagógicas. Porto Alegre: Artes Médicas, 1996.

CACHAPUZ, A. F. C. (Org.). Perspectivas de ensino de Ciências. 1. ed. Porto: Centro de Estudos de Educação em Ciências, 2000. (Formação de professores - Ciências, et al (Org.). A necessária renovação do ensino das Ciências. São Paulo: Cortez, 2005.

COLL, C.; MARCHESI, A.; PALACIOS, J. Desenvolvimento psicológico e educaçáo: transtornos do desenvolvimento e necessidades educativas especiais. 2. ed. Porto Alegre: Artmed, 2004.

DANTE, L. R. Didática da resoluçáo de problema. São Paulo: Ática, 1989.

D’AMBROSIO, U. Educaçáo Matemática: da teoria à prática. Campinas, Papirus, 2001a (Coleção Perspectiva em Educaçáo Matemática).

DECLARAÇÃO DE BUDAPESTE. Marco Geral de Açáo. 1999. Disponível em: <http://www.unesco.org/ science/wcs/esp/declaracion_s.htm>. Acesso em: 24 fev. 2014.

GLAT, R; FERNANDES E M. Da educação segregada à educação inclusiva: uma breve reflexẫo sobre os paradigmas educacionais no contexto da educação especial brasileira. Revista Inclusáo, n. 1, 2005.

HERNÁNDEZ, F.; VENTURA, M. A organizaçáo do currículo por projetos de trabalho. 5. ed. Porto Alegre: Artes Médicas, 1998.

MANTOAN, M. T. E. Ser ou estar eis a questáo: explicando o déficit intelectual. Rio de Janeiro: WVA, 1997.

MARTINS, J. S. O trabalho com projetos de pesquisa: do ensino fundamental ao ensino médio. São Paulo: Papirus, 2001. 
MAZZOTTA, M. J. S. Educaçáo especial no Brasil: história e políticas públicas. 2. ed. São Paulo: Cortez, 2002.

MENDES, I. A. Matemática e investigaçáo em sala de aula: tecendo redes cognitivas na aprendizagem. Sáo Paulo: Livraria de Física, 2009.

MINAYO, M. C. S. et al. (Orgs.). Pesquisa social: teoria, método e criatividade. 2. ed. Rio de Janeiro: Vozes, 1994. 80 p.

MORIN, E. A cabeça bem-feita: repensar a reforma, reformar o pensamento. 14. ed. Rio de Janeiro: Bertrand Brasil, 2003.

NOGUEIRA, N. Pedagogia dos projetos: etapas, papéis e atores. 4. ed. São Paulo: Érica, 2008.

Uma prática para o desenvolvimento das múltiplas inteligências: aprendizagem por projetos. 8. ed. São Paulo: Érica, 2007.

PAIS, L. C. Didática da matemática: uma análise da influência francesa. Belo Horizonte: Autêntica, 2006.

PAVANELLO, R. M. Formaçáo de possibilidades cognitivas em noçóes geométricas. Tese (Doutorado em Metodologia do Ensino) - Faculdade de Educaçáo, Universidade Estadual de Campinas. Campinas (SP), 1995.

PINHEIRO, N. A. M. Educaçấo crítico-reflexiva para um ensino médio científico-tecnológico: a contribuição do enfoque CTS para o ensino-aprendizagem do conhecimento matemático. Tese (Doutorado) - Universidade Federal de Santa Catarina. Florianópolis. SC. 2005.

SANTOMÉ, J. T. Globalizaçáo e interdisciplinaridade: o currículo integrado. Porto Alegre: Artes Médicas do Sul, 1998.

SHOGREN, K. A.; et al. Intellectual Disability: definition, classification and system of support. Washington (DC): AAIDD, 2010.

TOLEDO, M. B. A. Teoria e prática matemática: como dois e dois. 1. ed. São Paulo: FTD, 2010.

TUFANO, W. Contextualização. In: FAZENDA, I. C. Dicionário em Construçáo: Interdisciplinaridade. São Paulo: Cortez, 2001.

VYGOTSKY, L. S. Obras escogidas: fundamentos de defectología. Tomo. V. Madrid: Visor, 1997.

\section{Notas}

${ }^{1}$ A partir da Declaração de Montreal sobre Deficiência Intelectual, aprovada em 6/10/04 pela Organizaçáo Mundial de Saúde (OMS, 2004), em conjunto com a Organização Pan-Americana da Saúde (Opas), o termo "deficiência mental" passou a ser "deficiência intelectual".

${ }^{2}$ Em uma reuniấo da AAMR (Associaçăo Americana de Retardo Mental) em novembro de 2006 (2 anos após a Declaração de Montreal) decidiu-se que a partir de 01/01/2007 a AAMR passaria chamar-se Associação Americana de Deficiência Intelectual e do Desenvolvimento (AAIDD), que adotou e incorporou o termo "deficiência intelectual" na próxima publicação da 11ª Ediçăo do Manual "Deficiência Intelectual - Definição, Classificação e Níveis de Suporte", publicado em 2010.

${ }^{3} \mathrm{O}$ projeto foi aplicado, no ano de 2013 , as turmas estavam organizadas em ano. Atualmente a organização pedagógica na escola Especial está formalizada em ciclos.

${ }^{4}$ As atividades propostas neste artigo estão disponíveis na integra para consulta no endereço eletrônico <http://ppgect. pg.utfpr.edu.br/site/?page_id=344> ano 2015 .

\section{Correspondência}

Amanda Drzewinski de Miranda - Avenida Balduíno Taques, 2093, ap.33. Edifício Palazzo Murano. CEP: 84015-255, Ponta Grossa, Paraná, Brasil.

E-mail: amandadrzewinski@gmail.com - nilceiaamp@gmail.com

Recebido em 27 de abril de 2015

Aprovado em 17 de março de 2016

Revista Educação Especial | v. 29 | n. 56 | p. 695-708 | set./dez. 2016

Santa Maria

Disponível em: <http://www.ufsm.br/revistaeducacaoespecial> 